\section{Hiperhomocisteinemia y mutación C677T de la metilentetrahidrofolato reductasa}

\section{Sr. Director:}

La homocisteína se perfila como un serio candidato a factor de riesgo cardiovascular, siendo grande la expectación y debate que está provocando en toda reunión o simposio que se celebra sobre temas relacionados con la enfermedad trombótica.

Hemos leído con interés el artículo del Dr. Suárez García y colaboradores en su revista, a propósito del significado clínico de la homocisteína (1), y observamos que se hace una escueta referencia a la mutación C677T del gen de la metilentetrahidrofolato reductasa (C677T MTHFR). Nuestra intención en esta reseña es hacer una aportación al conocimiento de la biología y epidemiología de esta mutación.

Se conoce que el $73 \%$ de los individuos con niveles de homocisteína superiores a 40 micromol/litro son homocigotos para la mutación C677T MTHFR (2). En homocigosis esta mutación provoca una variante termolábil de la enzima MTHFR que presenta una actividad residual del $50 \%$ en su función de transferencia de grupos metilo en la vía de la remetilación de la homocisteína. Puesto que esta enzima usa como cofactor ácido fólico, la actividad enzimática se ve drásticamente reducida en situaciones carenciales de folatos (3-6).

Hay que tener en cuenta que la variabilidad preanalítica que afecta a la determinación de la homocisteína (7), y la multitud de factores dietéticos que pueden influir en los niveles de esta sustancia en los líquidos corporales, hacen que probablemente la valoración laboratorial relacionada con el metabolismo de la metionina más fiable a nivel individual sea el estudio de las mutaciones que se saben relacionadas con hiperhomocisteinemia. Entre éstas destaca por su frecuencia en población europea (5$15 \%$ ) la mutación C677T MTHFR.

En nuestra experiencia preliminar en 62 pacientes con accidentes isquémicos cerebrovasculares agudos (ACVA) menores de 50 años o con historia personal o familiar de trombofilia (edad media 41,6 años), hemos encontrado un $17,74 \%$ de homocigotos y un 45,16\% de heterocigotos para C677T MTHFR. Estos resultados indican una frecuencia génica del alelo mutante de 0,403 en una población de pacientes con ACVA y ausencia de factores de riesgo vascular clásicos (8). A primera vista, parece que esta mutación puede tener un papel de primer orden en el desarrollo de la enfermedad aterotrombótica, pero desconocemos la frecuencia génica de esta mutación en la población general, por lo que no podemos afirmar este extremo. El conocimiento de este polimorfismo nos permite explicar asociaciones familiares de fenómenos trombóticos que permanecían ocultas en nuestros estudios previos a la incorporación de las técnicas de biología molecular (8).

Varios estudios metaanalíticos concluyen que no puede considerarse C677T MTHFR como factor de riesgo independiente en patología trombótica, pero la gran variabilidad de poblaciones genéticamente distintas que abarcan y sus distintos hábitos dietéticos, hacen que se llegue a conclusiones que podrían no ser aplicables a poblaciones concretas. La heredabilidad de factores plasmáticos de sustancias relacionadas con la trombosis es muy alta, no hallándose globalmente diferencias significativas entre territorios venosos y arteriales. La heredabilidad de los niveles de homocisteína en sangre en familias con trombofilia es del $24,4 \%$ (9). Cada población, sobre la base de su herencia, hábitos y ambiente al que está sometida, tiene sus propios factores de riesgo vascular, dependientes en muchos casos de una interacción entre distintos genes entre sí y con el ambiente. Así, debemos comenzar a pensar en que, complementariamente a una "dieta mediterránea" existe una "genética mediterránea", y que la investigación de mutaciones como la C677T MTHFR puede contribuir en gran medida al conocimiento de los factores de riesgo de nuestra población.

\section{J. Ma Grasa Ullrich, M. Torres Gómez, B. Sánchez Marín*, M*. T. Calvo Martín**, J. A. García Erce, M. Giralt Raichs}

Servicios de Hematología y Hemoterapia, *Neurología, y**Uni dad de Genética. Hospital Universitario Miguel Servet. Zaragoza

1. Suárez García I, Gómez Cerezo JF, Ríos Blanco JJ, Barbado Hernández FJ, Vázquez Rodríguez JJ. La homocisteína. ¿El factor de riesgo cardiovascular del próximo milenio? An Med Interna (Madrid) 2001; 18: 211-7.

2. Guttomsen AB, Veland PM, Nesthus I, Nygard O, Schneede J, Vollset $\mathrm{SE}$, Refsum H. Determinants and vitamin responsiveness of intermediate hyperhomocysteinemia ( $>$ or $=40 \mathrm{micromol} / \mathrm{liter}$ ). The Hordaland Homocysteine Study. J Clin Invest 1996; 98: 2174-83.

3. Nygard O, Refsum H, Ueland PM, Vollset SE. Major lifestyle of plasma total homocysteine distribution. The Hordaland Homocysteine Study. Am J Clin Nutr 1998; 67: 263-70.

4. Dekou V, Gudnason V, Hawe E, Miller GJ, Stansbie D, Humphries SE. Gene-enviroment and gene-gene interaction in the determination of plasma homocysteine levels in healthy middle-aged men. Thromb Haemost 2001; 85: 67-74.

5. Frosst P, Blom HJ, Milos R, Goyette P, Sheppard CA, Matthews RG, Boers GH, den Heijer M, Kluijtmans LA, van den Heuvel LP, et al. A candidate genetic risk factor for vascular disease: a common mutation in the methylenetetrehydrofolate reductase. Nat Genet 1995; 10: 111-3.

6. Kluijtmans LA, van den Heuvel LP, Boers GH, Frosst P, Stevens EM, van Oost BA, den Heijer M, Trijblls FJ, Rozen R, Blom HJ. Molecular genetic analysis in mild hyperhomocysteinemia: a common mutation in the methylenetetrahydrofolate reductase gene is a genetic risk factor for cardiovascular disease. Am J Hum Genet 1996; 58: 35-41.

7. Aguirre C, Egurbide MV. Significado clínico de la homocisteína. Rev Clin Esp 2001; 201: 25-7.

8. Grasa JM, Díaz-Peiró S, Sánchez-Marín B, Torres M, Calvo MT, Montañés MA, Cortina T, Recaséns V, Lucía JF, García-Erce JA, Giralt M. Estudio preliminar de hipercoagulabilidad en pacientes con accidentes isquémicos cerebrales transitorios. Haematologica 2000; 85 (supl.3): 142.

9. Souto JC, Almasy L, Borrell M, Garí M, Martínez E, Mateo J, Stone WH, Blangero J, Fontcuberta J. Genetic determinants of hemostasis phenotypes in spanish families. Circulation 2000; 101: 1546-51.

Dolor torácico y marcada elevación enzimática.

Forma de presentación de la enfermedad de

\section{Mc Ardle}

\section{Sr. Director:}

Hemos leído con interés el artículo publicado en su revista de López Martin y cols. (l) "Enfermedad de Mc Ardle: descripción de cuatro hermanos con defícit de miofosforilasa". Hemos tenido la oportunidad de diagnosticar un nuevo caso en una paciente de edad avanzada, que acudió a nuestro hospital por intenso dolor torácico, objetivándose cifras muy elevadas de CPK por lo que, en un principio, se pensó en la posibilidad de patología isquémica cardíaca, y que a continuación se comenta:

Se trataba de una mujer de 64 años que ingresó por un cuadro de dolor torácico opresivo, irradiado a hombros, que no tenía relación con el ejercicio ni se modi;caba con la postura y que se repitió, en varias ocasiones, sin acompañarse de cortejo vegetativo. También, refería debilidad muscular generalizada de forma episódica, pero principanente en relación con el ejercicio. Entre sus antecedentes destacaba el hecho de ser consultada en dos ocasiones, hacía 12 y 2 años, por diversos motivos apreciándose alteraciones de enzimas musculares, a las que no se les dio mayor importancia, sin que tampoco se llegara a estudiar en ese sentido. 